\title{
Hemodiálisis con dializadores de poro grueso para tratar el fracaso renal agudo del paciente con Mieloma
}

\author{
Alexandra Mallol Domínguez - Ma José Folch Morro - Elena Renau Ortells - Vicente Cerrillo García
}

Diplomados en enfermería

Unidad de Diálisis. Hospital General de Castellón

\section{Introducción}

El Mieloma múltiple ( M M) es una neoplasia de células plasmáticas anormales con capacidad para sintetizar y secretar inmunoglobulinas, que forman el pico monoclonal en sangre $y / 0$ orina. La enfermedad tiene una incidencia de tres casos anuales por 100.000 habitantes. Representa el $1 \%$ de todas las neoplasias y el $10 \%$ de los padecimientos hematológicos malignos ${ }^{1}$.

En los años 60 Carbone y Cols. Reconocieron la anemia, la calcemia y la función renal, como variables clínicas que predecían una evolución desfavorable de la enfermedad. Con el tiempo se han identificado también el valor de la albúmina sérica, la extensión de la afección esquelética, la edad y el recuento de plaquetas y más recientemente la capacidad física funcional ${ }^{2}$.

La forma de afectación renal más frecuente en el Mieloma consiste en la formación de extensos cilindros tubulares, condicionando la patología como "Riñón del Mieloma" o "Nefropatía por cadenas ligeras". Estos depósitos intratubulares están formados fundamentalmente por las cadenas ligeras de las inmunoglobulinas. Éstas, al estar en concentraciones muy elevadas en el plasma, son filtradas y llegan a los túbulos en gran cantidad, de forma que se supera la capacidad de metabolización tubular y dan lugar a proteinuria por hiperflujo. Bajo ciertas circunstancias, estas ca-

\footnotetext{
Correspondencia:

Alexandra Mallol Domínguez

E-mail: alexmallol@hotmail.com
}

denas ligeras precipitan y forman los mencionados cilindros, que condicionan atrofia tubular y fibrosis intersticial ${ }^{3}$.

Con cifras menores de $5 \mathrm{mg} / \mathrm{dl}$ de creatinina en suero es posible una mejoría de la función renal después de hidratación, corrección de la calcemia y uricemia en el $90 \%$ de las ocasiones. Los valores entre 6 y $15 \mathrm{mg} /$ dl requieren diálisis, tienen mayor retraso en la recuperación hematopoyética después de quimioterapia y a pesar de un tratamiento oportuno, la restauración de la función renal solo ocurre en el $50 \%$ de los pacientes. Cuando la creatinina es mayor de $15 \mathrm{mg} / \mathrm{dl}$ la lesión renal es tan extensa que probablemente cerca de un $100 \%$ no logren recuperarse 4 .

La prevención del desarrollo del Fracaso Renal Agudo (FRA) es el mejor medio para evitarlo, pero no existe ningún factor predictivo que pueda indicar mayor riesgo de desarrollarlo. El desarrollo de un FRA en el mieloma tiene un origen multifactorial. Así la eliminación urinaria de cadenas ligeras lesiona las células tubulares y origina cilindros con la correspondiente obstrucción tubular, depleción de volumen, hipercalcemia y se suelen añadir otros factores como la administración de contraste ${ }^{5}$.

El principal tratamiento de estos pacientes es la quimioterapia, con el objetivo de disminuir la producción de cadenas ligeras. En los casos que existen fallo renal secundario al depósito intratubular, la hemodiálisis y la plasmaféresis se presentan como una opción de tratamiento adyuvante. El objetivo de estas técnicas es eliminar el mayor porcentaje de cadenas ligeras circulantes del plasma6. 
Revisando bibliografía podemos ver que la efectividad de la Plasmaféresis en aclarar cadenas ligeras en los pacientes con fallo renal agudo y riñón del mieloma es dudosa. Un tratamiento alternativo sería aclarar cadenas ligeras mediante hemodiálisis con dializadores de nueva generación perdedores de proteínas (poros muy gruesos). La hemodiálisis con dializadores de poro grueso junto con la quimioterapia es un avance significativo en el tratamiento del mieloma múltiple en pacientes con insuficiencia renal.

Presentamos el caso de un fallo renal agudo secundario a riñón del mieloma, con buena respuesta al tratamiento de hemodiálisis.

\section{Objetivo}

Descripción del caso clínico de un paciente con riñón del mieloma tratado con filtro Teralithe para disminuir niveles de cadenas ligeras y así disminuir el riesgo de fracaso renal irreversible.

\section{Caso clínico}

Paciente de 72 años que ingresa por deterioro renal agudo. Presenta hipertensión arterial (HTA), hipercolesterolemia y no padece diabetes Mellitus. En agosto de 2008 sufrió una fractura patológica de húmero por la que se intervino con colocación de clavo endomedular. En la histología se diagnostica neoplasia de células plasmáticas. Se procede a estudio de extensión con infiltración plasmática de médula ósea, con un pico monoclonal IgG lambda muy débil. Se decide iniciar primero radioterapia sobre la fractura patológica (Noviembre 08). A finales de Noviembre sigue mostrando pico monoclonal IgG lambda muy débil en suero pero un intenso pico monoclonal de cadenas ligeras lambda en orina con proteinuria de 1,8g/día y al mes siguiente de $2,3 \mathrm{~g} /$ día.

El paciente es diagnosticado de Mieloma BenceJones $(\lambda)$ estadio IIIB, con tratamiento citostático: Bortezomid y Dexametasona. El fracaso renal agudo fue de 15 días de evolución con una creatinina de $6 \mathrm{mg} / \mathrm{dl}$, por lo que se deriva a Nefrología para iniciar sesiones de Hemodiálisis con sustracción de cadenas ligeras.

\section{Material y métodos}

Para este caso tuvimos que realizar un protocolo de la sesión de Hemodiálisis para este paciente con MM. Se realizaron 14 sesiones de 5 horas de duración y sacamos analíticas en las sesiones $1,2,3,4,5,6,9$ y 12 . En la analítica pre sacamos bioquímica (perfil diálisis, IgGAM, B2 Microg, y cadena ligera libre), hormonas y hemograma y en la analítica post lo mismo que se sacaba en la analítica pre más líquido del Quantiscan (albúmina y cadenas ligeras).

Utilizamos el monitor Integra con el Quantiscan activado, ya que hacíamos una recogida continua de muestras. El dializador fue el HC1100, con una superficie $1.1 \mathrm{~m} 2$. Para el purgado se utilizó Prontoprime de $2000 \mathrm{ml}$ pero teniendo la precaución de que no entrara aire en el dializador, es decir, cebando primero la línea arterial antes de conectarla al dializador.

- El acceso vascular fue catéter yugular tunelizado derecho.

- Durante el cebado de baño poníamos la Ultrafiltración a $1-2 \mathrm{l} / \mathrm{h}$.

- La velocidad de la QB (flujo sanguíneo) fue siempre $250 \mathrm{ml} / \mathrm{min}$.

- Se administraba fraxiparina $0.3 \mathrm{mg} / \mathrm{dl}$ al inicio de la sesión.

En la última hora de hemodiálisis se pasaban 2 frascos de $50 \mathrm{ml}$ de albúmina al $20 \%$ ya que según el fabricante durante la sesión se pierde $1.5 \mathrm{~g} / \mathrm{h}$ de albúmina con el flujo de baño a $500 \mathrm{ml} / \mathrm{min}$.

En este paciente, al finalizar la sesión, se administraba por infección del catéter tunelizado Vancomicina lgr iv y Levofloxacino $500 \mathrm{mg}$ iv.

\section{Resultados}

Como resultados podemos observar el descenso de cadenas ligeras en cada sesión y también su descenso desde su inicio al fin de tratamiento, siendo el inicio de $97 \mathrm{mg} / \mathrm{dl}$ y el final $1.27 \mathrm{mg} 7 \mathrm{dl}$. (Tabla 1 ).

La Hemoglobina aumentó durante su estancia hospitalaria de $8.2 \mathrm{gr} / \mathrm{dl}$ a $10.4 \mathrm{gr} / \mathrm{dl}$, recibiendo únicamente tres concentrados de Hematíes. 


\begin{tabular}{|l|c|c|c|c|c|c|c|c|}
\hline SESIONES & $\mathbf{1}$ & $\mathbf{2}$ & $\mathbf{3}$ & $\mathbf{4}$ & $\mathbf{5}$ & $\mathbf{6}$ & $\mathbf{9}$ & $\mathbf{1 2}$ \\
\hline $\begin{array}{l}\text { Cadena ligera } \\
\text { pre } \\
\mathrm{mg} / \mathrm{dl}\end{array}$ & $\mathbf{9 7}$ & 50 & 22.4 & 10.8 & 5 & 3.4 & 2.4 & $\mathbf{1 . 2 7}$ \\
\hline post & $\mathbf{5 3}$ & 38 & 8.6 & 7.4 & 4.4 & 2.8 & 1.69 & $\mathbf{0 . 7}$ \\
\hline
\end{tabular}

Tabla 1.Resultados cadenas ligeras lambda en sangre

EI PH y el Fósforo no sufrieron cambios significativos en todo el estudio.

Se mantuvo la diuresis durante todo el proceso de Hemodiálisis $+1100 \mathrm{cc} /$ diarios.

La UF total osciló entre $\pm 1500 \mathrm{ml}$ por sesión, siendo bien tolerada por el paciente, exceptuando una hipotensión aislada que remontó con solo 200 cc de Suero Fisiológico + 100cc de Gelafundina. En casi todas las sesiones se tuvo que cambiar la línea venosa por aumento de Presión Venosa y grandes coágulos en cámara venosa, a pesar de poner fraxi 0.3 ( heparina de bajo peso molecular).

La urea y la creatinina fueron descendiendo progresivamente durante todas las sesiones. (Tabla 2 ).

La QB y QD se mantuvieron constantes en todas las sesiones. (Tabla 3).

El fracaso renal del señor mejoró reduciendo la creatinina de $6 \mathrm{mg} / \mathrm{dl}$ a una de $1.13 \mathrm{mg} / \mathrm{dl}$., estos datos no están reflejados en la tabla 2 ya que son analíticas de consulta.

El paciente recuperó su función renal pasando del estadio V al III, y fue retirado de Hemodiálisis para pasar a ser controlado en Consultas Externas de Nefrología, ya que en las analítaicas realizadas en los

\begin{tabular}{|c|c|c|c|c|c|c|c|c|c|}
\hline SESIONES & 1 & 2 & 3 & 4 & 5 & 6 & 9 & 12 & 14 \\
\hline $\begin{array}{l}\text { B2 Microglob } \\
\text { pre } \\
\mathrm{mg} / \mathrm{l}\end{array}$ & 11.2 & 10.4 & 10.3 & 15.2 & 15.3 & 10.8 & 10.1 & 6.6 & \\
\hline post & 5.1 & 4.3 & 5.4 & 9.5 & 7.6 & 2.1 & 2.2 & 6.6 & \\
\hline $\begin{array}{l}\text { Albumina } \\
\text { pre } \\
\text { g/dl }\end{array}$ & 3.8 & 4 & 3.6 & 3.5 & 3.7 & 3.6 & 3.8 & 3.9 & 3.72 \\
\hline post & 4 & 3.8 & 3.6 & 3.5 & 3.6 & 4.1 & 3.8 & 3.8 & \\
\hline $\begin{array}{l}\text { Urea } \\
\text { pre } \\
\mathrm{mg} / \mathrm{dl}\end{array}$ & 131 & 84 & 163 & 128 & 104 & 70 & 100 & 135 & 97 \\
\hline post & 43 & 28 & 66 & 63 & 34 & 34 & 46 & 73 & \\
\hline $\begin{array}{l}\text { Fósforo } \\
\text { pre } \\
\mathrm{mg} / \mathrm{dl}\end{array}$ & 2.4 & 3.3 & 1.8 & 2.5 & 2.4 & 3.6 & 3.1 & 2.8 & \\
\hline post & 2.5 & 2.4 & 1.6 & 2.7 & 2.1 & 2.2 & 2.6 & 2.9 & \\
\hline $\begin{array}{l}\text { Creatinina } \\
\text { pre } \\
\mathrm{mg} / \mathrm{dl}\end{array}$ & 4.9 & 3.32 & 6.25 & 6.27 & 5.36 & 3.5 & 3.43 & 3.86 & 3.33 \\
\hline post & 2.01 & 1.48 & 3.04 & 3.58 & 2.28 & 2 & 1.78 & 2.38 & \\
\hline $\begin{array}{l}\mathrm{Hb} \\
\mathrm{pre} \\
\mathrm{g} / \mathrm{dl}\end{array}$ & 8.2 & 8.1 & 10.8 & 9 & 10.1 & 10.1 & & 11.8 & \\
\hline post & 7.4 & 13 & 9.9 & 10.5 & & & & & \\
\hline $\begin{array}{l}\text { PH } \\
\text { pre }\end{array}$ & 7.41 & 7.44 & 7.39 & 7.45 & 7.41 & & & & \\
\hline post & 7.44 & 7.49 & 7.44 & 7.41 & 7.35 & & & & \\
\hline
\end{tabular}

Tabla 2. Resultados bioquímica y hemograma 


\begin{tabular}{|l|c|c|c|c|c|c|c|c|c|c|c|c|c|c|}
\hline \multicolumn{1}{|c|}{ SESIONES } & $\mathbf{1}$ & $\mathbf{2}$ & $\mathbf{3}$ & $\mathbf{4}$ & $\mathbf{5}$ & $\mathbf{6}$ & $\mathbf{7}$ & $\mathbf{8}$ & $\mathbf{9}$ & $\mathbf{1 0}$ & $\mathbf{1 1}$ & $\mathbf{1 2}$ & $\mathbf{1 3}$ & $\mathbf{1 4}$ \\
\hline $\begin{array}{l}\text { QB media diaria } \\
\mathrm{ml} / \mathrm{min}\end{array}$ & 250 & 250 & 250 & 250 & 250 & 250 & 250 & 250 & 250 & 260 & 250 & 250 & 250 & 250 \\
\hline QD ml/min & 500 & 500 & 500 & 500 & 500 & 500 & 500 & 500 & 500 & 500 & 500 & 500 & 500 & 500 \\
\hline UF total MI & 1200 & 1320 & 1560 & 1720 & 2000 & 2000 & 1850 & 2000 & 900 & 1900 & 1700 & 2800 & 1660 & 1200 \\
\hline
\end{tabular}

Tabla 3. Valores Qb Qd y ultrafiltración

días posteriores a la última sesión de HD la urea y creatinina se mantuvieron dentro de los valores normales para un estadio III

\section{Discusión}

La Hemodiálisis con dializadores de gran poro son efectivos en aclarar los niveles de Cadena Ligera Libre en suero, facilitando la recuperación del fracaso renal agudo en el riñón del mieloma. Su uso junto con la quimioterapia es una alternativa más efectiva que la Plasmaféresis ${ }^{7}$.

La combinación de tratamiento médico junto con hemodiálisis utilizando dializadores de poro grueso es hasta ahora el método más eficaz para disminuir los niveles de cadenas ligeras libres ${ }^{8}$ como podemos comprobar en este caso clínico.

Vemos un claro descenso de las cadenas ligeras en cada sesión, lo que nos demostraría la gran eficacia de este tipo de dializador.

Al ver la coagulación diaria que sufría el circuito extracorpóreo, creemos que haría falta administrar más anticoagulante o hacerlo de forma fragmentada.

Creemos que la inmediata inclusión en hemodiálisis fue uno de los factores determinantes para obtener un resultado positivo.

En este estudio la QB fue 250cc y QD 500cc ya que según el estudio de Morgera y Hutchison a estas velocidades se consigue un buen aclaramiento de cadenas ligeras y una mínima pérdida de albúmina.

\section{Conclusiones}

El tratamiento de IRC en pacientes con mieloma múltiple es satisfactorio siempre que se inicie un tratamiento precoz una vez detectada la enfermedad.
El nivel de cadenas ligeras lambda disminuyó al final el tratamiento hemodialítico remitiendo del estadio $\mathrm{V}$ de la IRC al estadio III, con lo que podemos decir que el fracaso renal del MM es un proceso reversible.

En conclusión, podemos decir que el paciente terminó su tratamiento con éxito y pasó a ser controlado en las Consultas Externas de Nefrología.

\section{Bibliografía}

1. Fernando Romero-García. Novedades en Mieloma Múltiple. Grac Méd Méx Vol.139, Suplemento No.2, 2003.

2. José Luis Delgado-Lamas. Factores pronóstico de valor en mieloma múltiple. Grac Méd Méx Vol.139, Suplemento No.2,2003.

3. F. Anaya. AFT en enfermedades renales. En Aféresis terapéutica. Ed. Capitel Ediciones S.L. 2005. Pag: 163-164.

4. Badros A, Barlogie B, Siegel E. Results of autologous stem cell transplantin in MM patients with renal failure. Br.J.Haematol 2001;114:822-829.

5. E. Gozález Parra. Prevención de FRA asociado a depósitos intratubulares de origen endógeno: rabdomiólisis, mieloma múltiple y síndrome de lisis tumoral. Guías SEN. Nefrología. Volumen 27. Suplemento 3. 2007. Pág 78.

6. F. Levy. Plasmaféresis como tratamiento adyuvante en el fallo renal agudo secundario a riñón del mieloma. Nefrología. 2009.29 (3): 283-284.

7. G. Martin Reyes. Tratamiento del fracaso renal agudo en el riñón del mieloma con hemodiálisis utilizando filtros de poro grande (Hight Cut -off).S.E.N. Póster presentado al 38 congreso de la SEN. 2008. Disponible en http://38 senefro. postersessiononline.es P 212 .

8. Kolita Basnayake. of cast nephropathy following free light chain removal by haemodialysis in a patient with multiple myeloma: a case report. J. Med. Case Reports.2008;2:380Resolution. 